\title{
Cause of Mortality after Radical Prostatectomy and the Impact of Comorbidity in Men with Prostate Cancer: A Multi-institutional Study in Korea
}

\section{Sahyun Pak, MD 1 \\ Dalsan You, MD, PhD² \\ In Gab Jeong, MD, PhD² \\ Dong-Eun Lee, MSc ${ }^{3}$ \\ Sung Han Kim, MD, PhD ${ }^{1}$ \\ Jae Young Joung, MD, $P h D^{1}$ \\ Kang-Hyun Lee, MD, PhD ${ }^{1}$ \\ Jun Hyuk Hong, MD, PhD² \\ Choung-Soo Kim, MD, PhD² \\ Hanjong Ahn, MD, PhD²}

${ }^{1}$ Department of Urology, Center for Urologic Cancer, National Cancer Center, Goyang,

${ }^{2}$ Department of Urology, Asan Medical Center, University of Ulsan College of

Medicine, Seoul, ${ }^{3}$ Biostatistics Collaboration

Team, Research Core Center,

Research Institute and Hospital,

National Cancer Center, Goyang, Korea

Correspondence: Hanjong Ahn, MD, PhD Department of Urology, Asan Medical Center, University of Ulsan College of Medicine, 88 Olympic-ro 43-gil, Songpa-gu,

Seoul 05505, Korea

Tel: 82-2-3010-3733

Fax: 82-2-477-8928

E-mail: hjahn@amc.seoul.kr

Co-correspondence: Jae Young Joung, MD, PhD Department of Urology and Center for

Urologic Cancer, Research Institute and

Hospital of National Cancer Center,

323 Ilsan-ro, Ilsandong-gu, Goyang 10408, Korea

Tel: 82-31-920-1740

Fax: 82-31-920-2799

E-mail: urojy@ncc.re.kr

Received April 7, 2020

Accepted July 1, 2020

Published Online July 3, 2020

\section{Purpose}

This study aimed to examine the causes of death in Korean patients who underwent radical prostatectomy for prostate cancer and investigate the relationship between comorbidity and mortality.

\section{Materials and Methods}

We conducted a retrospective multicenter cohort study including 4,064 consecutive patients who had prostate cancer and underwent radical prostatectomy between January 1998 and June 2013. The primary endpoint of this study was all-cause mortality, and the secondary endpoints were cancer-specific mortality (CSM) and other-cause mortality (OCM). Charlson comorbidity index (CCl) was calculated to assess the comorbidities of each patient.

\section{Results}

Of 4,064 patients, 446 (11.0\%) died during follow-up. The cause of death was prostate cancer in 132 patients (29.6\%), other cancers in 121 patients (27.1\%), and vascular disease in 57 patients $(12.8 \%)$ in our cohort. The overall 10-year CSM rate was lower than the OCM rate $(4.6 \%$ vs. $10.5 \%)$. The 10 -year CSM rate was lower than the OCM rate in low- to intermediate-risk group patients (1.2\% vs. $10.6 \%)$, whereas they were similar in high-risk group patients (11.8\% vs. $10.1 \%)$. In the multivariable analysis, $\mathrm{CCl}$ was independently associated with all-cause mortality after radical prostatectomy, regardless of age and pathologic features.

\section{Conclusion}

Death from prostate cancer was rare in Korean men who underwent radical prostatectomy. Clinicians should be aware of the possibility of overtreatment of low-risk prostate cancer in men with significant comorbidity. Our findings may help to facilitate counseling and plan management in this patient group.

\section{Key words}

Prostatic neoplasms, Survival, Comorbidity

\section{Introduction}

Prostate cancer remains the most commonly diagnosed cancer in men worldwide [1]. Men with prostate cancer are generally considered to have favorable survival outcomes
$[2,3]$. Many studies have reported low prostate cancer-specific mortality (CSM) rates in men with non-metastatic prostate cancer, thus highlighting the importance of other causes of death. A recent study reported that surgical treatment was not associated with significantly lower 20-year overall mor- 
tality or CSM than that in men with localized prostate cancer who are assigned to observation [4]. However, despite the emergence of conservative treatment, men with prostate cancer are most likely to be treated with radical prostatectomy [5].

Medical comorbidity is common among the aging population with cancer, and this affects treatment efficacy [6]. Comorbidities have a particularly profound impact on the overall survival in men with prostate cancer as prostate CSM is low. In men with prostate cancer, the assessment of long-term other-cause mortality (OCM) is important for the selection of patients who have a high probability of experiencing survival benefit from aggressive radical treatment. Administering radical treatment for prostate cancer in men with low life expectancy due to other comorbidities may lead to overtreatment [7]. One study pointed out that men with significant comorbidity were often over-treated for low-risk prostate cancer [8]. Although several studies have reported on the causes of death after radical prostatectomy in Western populations $[9,10]$, these results may not be generalizable due to geographic and ethnic variations in prostate cancer characteristics and the prevalence of comorbidities.

In this multicenter study, we aimed to evaluate the causes of death after radical prostatectomy for prostate cancer in a Korean cohort. We also assessed the impact of comorbidity on mortality after radical prostatectomy.

\section{Materials and Methods}

\section{Study design}

To focus on survival outcomes after radical prostatectomy, patients who had received neoadjuvant or adjuvant therapy, had not achieved undetectable prostate-specific antigen (PSA) after surgery, or had inadequate clinical information were excluded from the analysis. The records of 4,064 men with prostate cancer who underwent radical prostatectomy (3,210 patients in Asan Medical Center and 854 patients in the National Cancer Center) between January 1998 and June 2013 were reviewed. Patient data, including demographic and clinical characteristics, treatment-related variables, and survival outcomes, were evaluated retrospectively. For the assessment of comorbidities among the enrolled patients, the Charlson comorbidity index (CCI) and age-adjusted CCI of each patient were calculated [11].

The levels of PSA were followed up postoperatively at 3-month intervals for the first 2 years, 6-month intervals for the third and fourth years, and annually thereafter. Biochemical recurrence was defined as two consecutive rises in the PSA level of $\geq 0.2 \mathrm{ng} / \mathrm{mL}$ after radical prostatectomy. The decision on secondary treatment modalities after biochemical recurrence, including salvage radiotherapy, androgen deprivation therapy, or surveillance, was based on patient's
Table 1. Clinical and pathological characteristics of patients

\begin{tabular}{|c|c|}
\hline & Total $(n=4,064)$ \\
\hline Age, mean (yr) & 65.1 \\
\hline$<50$ & $74(1.8)$ \\
\hline $50-60$ & $763(18.8)$ \\
\hline $60-70$ & $2,055(50.6)$ \\
\hline $70-80$ & $1,154(28.4)$ \\
\hline$\geq 80$ & $18(0.4)$ \\
\hline Body mass index, mean $\left(\mathrm{kg} / \mathrm{m}^{2}\right)$ & 24.7 \\
\hline \multicolumn{2}{|l|}{ Comorbidity } \\
\hline Hypertension & $1,759(43.3)$ \\
\hline Diabetes mellitus & $638(15.7)$ \\
\hline Other malignancy & $141(3.5)$ \\
\hline Heart disease & $190(4.7)$ \\
\hline Cerebrovascular disease & $113(2.8)$ \\
\hline Liver cirrhosis & $50(1.2)$ \\
\hline End-stage renal disease & $6(0.1)$ \\
\hline Chronic obstructive pulmonary disease & $112(2.7)$ \\
\hline \multicolumn{2}{|l|}{ Charlson comorbidity index } \\
\hline 0 & $2,993(73.6)$ \\
\hline 1 & $380(9.4)$ \\
\hline 2 & $543(13.4)$ \\
\hline$\geq 3$ & $148(3.6)$ \\
\hline Prostate-specific antigen, mean $(\mathrm{ng} / \mathrm{mL})$ & 13.0 \\
\hline \multicolumn{2}{|l|}{ NCCN risk group } \\
\hline Low & $1,280(31.5)$ \\
\hline Favorable intermediate & $1,041(25.6)$ \\
\hline Unfavorable intermediate & 483 (11.9) \\
\hline High & $1,260(31.0)$ \\
\hline \multicolumn{2}{|l|}{ Pathologic Gleason score } \\
\hline Unknown & $129(3.2)$ \\
\hline 6 & $909(22.4)$ \\
\hline $3+4$ & $1,368(33.6)$ \\
\hline $4+3$ & $857(21.1)$ \\
\hline 8 & $343(8.4)$ \\
\hline $9-10$ & $458(11.3)$ \\
\hline \multicolumn{2}{|l|}{ Pathologic T category } \\
\hline $\mathrm{T} 2$ & $2,573(63.4)$ \\
\hline T3a & $989(24.3)$ \\
\hline T3b-T4 & $502(12.3)$ \\
\hline Positive lymph nodes & $224(5.5)$ \\
\hline Positive surgical margins & $1,309(32.2)$ \\
\hline
\end{tabular}

Values are presented as number (\%) unless otherwise indicated. NCCN, National Comprehensive Cancer Network.

or physician's discretion. Abdominopelvic computed tomography and bone scanning were routinely performed at the time of biochemical relapse after radical prostatectomy and biochemical progression after secondary treatment. Radiographic progression was evaluated using computed tomography or magnetic resonance imaging for soft-tissue disease and bone scanning for bone disease. Survival was measured from the date of radical prostatectomy until the date 
Table 2. Causes of death after radical prostatectomy

\begin{tabular}{|cc|}
\hline Cause of death & Total $(\mathbf{n}=446)$ \\
\hline Prostate cancer & $132(29.6)$ \\
\hline Non-prostate cancer & $219(49.1)$ \\
\hline Other malignancy & $121(27.1)$ \\
\hline Lung & $25(5.6)$ \\
\hline Liver & $11(2.5)$ \\
\hline Colon, rectum, and anus & $8(1.8)$ \\
\hline Stomach & $19(4.2)$ \\
\hline Biliary tract and pancreas & $29(6.5)$ \\
\hline Hematopoietic malignancy & $12(2.7)$ \\
\hline Bladder & $7(1.6)$ \\
\hline Others & $10(2.2)$ \\
\hline Vascular disease & $57(12.8)$ \\
\hline Coronary heart disease & $31(7.0)$ \\
\hline Cerebrovascular disease & $26(5.8)$ \\
\hline Chronic pulmonary disease & $22(4.9)$ \\
\hline Chronic liver disease & $5(1.1)$ \\
\hline Other causes & $14(3.1)$ \\
\hline Unknown & $95(21.3)$ \\
\hline
\end{tabular}

Values are presented as number (\%).

of death. The cause of death was determined according to medical records.

Four-tier National Comprehensive Cancer Network (NC$\mathrm{CN}$ ) risk groups defined by the guidelines were as follows: low risk: stage T1-T2a, Gleason score $(\mathrm{GS}) \leq 6$, and PSA $<10$ $\mathrm{ng} / \mathrm{mL}$; favorable intermediate risk: one intermediate-risk factor (IRF, that is, stage T2b-T2c or GS 7 or PSA $10-20 \mathrm{ng} /$ $\mathrm{mL}$ ), GS 6 or $3+4$, and $<50 \%$ biopsy cores positive; unfavorable intermediate risk: two or three IRFs, GS $4+3$, and $\geq 50 \%$ biopsy cores positive; high risk: stage T3a or GS 8-10 or PSA $>20 \mathrm{ng} / \mathrm{mL}$ [12]. Cancer of the Prostate Risk Assessment Postsurgical (CAPRA-S) score was also calculated based on preoperative PSA, pathologic GS, positive surgical margin, presence of extracapsular extension, seminal vesicle invasion, and lymph node involvement [13].

Clinical and pathological data were expressed as frequencies and means. Survival outcomes were determined using the Kaplan-Meier method and compared with log-rank tests. Significant prognostic factors for survival were assessed by multivariate analysis using the Cox proportional hazard model with stepwise backward elimination approach. Competing risk regression was performed to test the association of predictor variables after accounting for prostate CSM and OCM. All statistical tests were two-tailed, with a significance level of 0.05. All statistical analyses were performed using SAS ver. 9.4 (SAS Institute Inc., Cary, NC) and R ver. 3.5.2 (R Foundation for Statistical Computing, Vienna, Austria).

\section{Ethical statement}

The study protocol was approved by the institutional

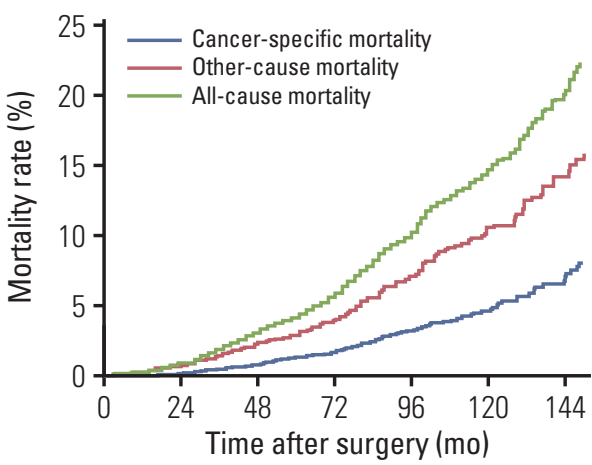

Fig. 1. Survival outcomes of the overall population.

review board of Asan Medical Center and National Cancer Center, Korea (AMC 2017-1036 and NCC 2018-0123). Informed consent was waived.

\section{Results}

The clinical and pathological characteristics of the 4,064 men with prostate cancer who underwent radical prostatectomy in the two study centers, along with the baseline comorbidities, are summarized in Table 1. The median follow-up duration for enrolled patients was 92.6 months. Approximately $26.4 \%$ of the patients had CCI $\geq 1$. During follow-up, 446 patients died at a median of 74.7 months after radical prostatectomy. The cause of death was prostate cancer in 132 patients (29.6\%), other causes in 219 patients $(49.1 \%)$, and unknown in 95 patients $(21.3 \%$ ) (Table 2).

The 10-year all-cause mortality rate was $15.5 \%$ in the overall population (Fig. 1). The 10-year CSM rate was lower than the OCM rate (4.6\% vs. $10.5 \%$ ) (Fig. 1). Comparisons between CSM and OCM stratified by preoperative risk groups are shown in Fig. 2A. The 10-year CSM rate was lower than the OCM rate in low- to intermediate-risk group patients $(1.2 \%$ vs. $10.6 \%)$, but both were similar in high-risk group patients (11.8\% vs. $10.1 \%)$.

The 10-year CSM rate was lower than the OCM rate in patients with pT2 (1.0\% vs. $10.6 \%)$ and pT3a ( $5.4 \%$ vs. $10.2 \%)$ cancers. However, in patients with pT3b cancers, the 10-year CSM rate was higher than the OCM rate $(20.1 \%$ vs. $10.4 \%)$. The 10-year CSM rate was lower than the OCM rate in patients with pathologic GS of $\leq 7(1.5 \%$ vs. $10.3 \%)$. In patients with pathologic GS of 8-10, there was a trend toward having a higher 10-year CSM rate than OCM rate (14.8\% vs. $11.3 \%$ ). A comparison between CSM and OCM according to the preoperative NCCN risk groups and age-adjusted CCI is shown in Fig. 3. The 10-year CSM rate was higher than the OCM rate only in NCCN high-risk patients with age-adjusted CCI of $<3$.

In the multivariable analyses, CCI was significantly asso- 

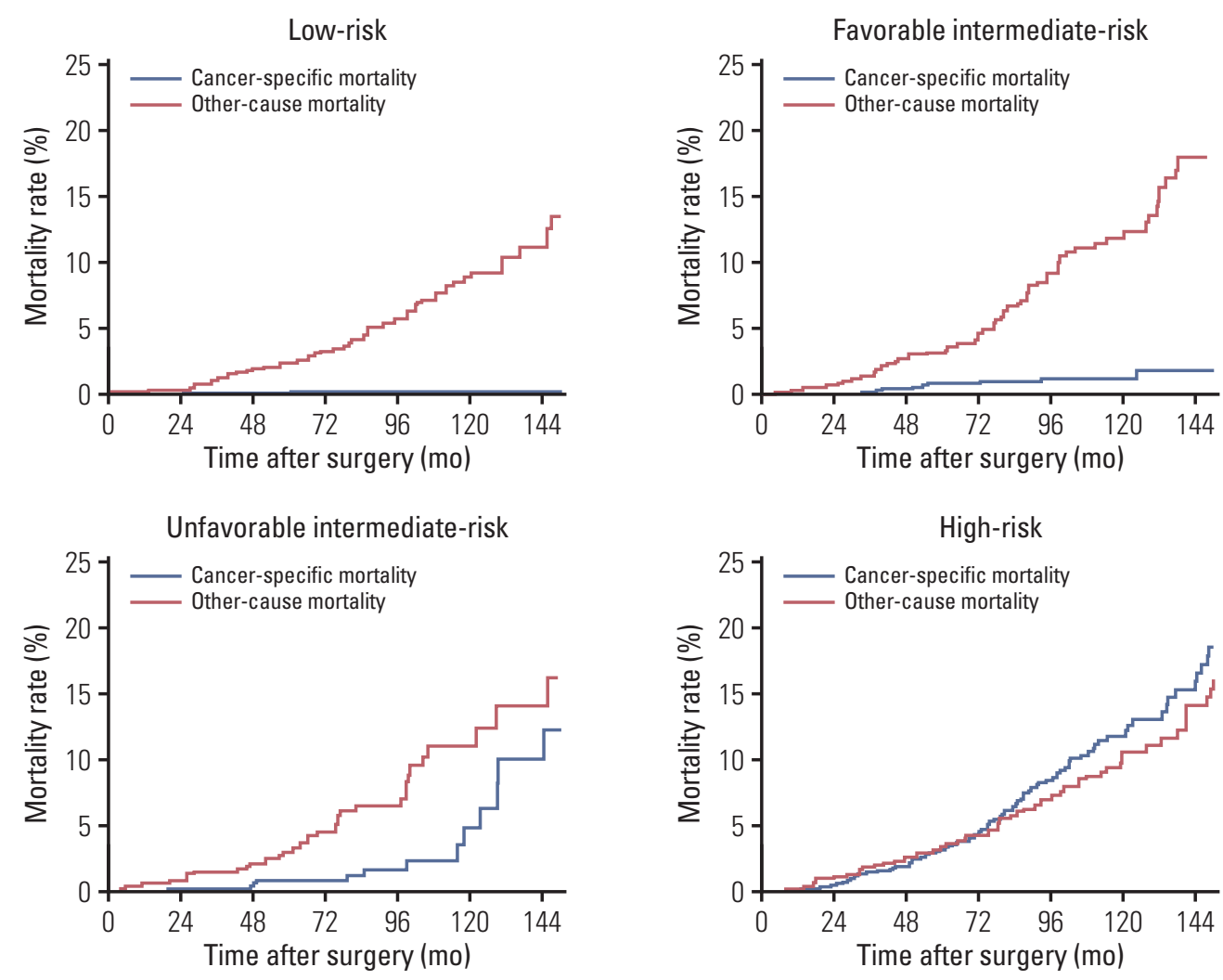

Fig. 2. Survival outcomes according to the preoperative National Comprehensive Cancer Network risk group.

ciated with overall mortality after radical prostatectomy, regardless of age and pathologic features (Table 3). Competing risks regression analysis showed that $\mathrm{CCI}$ was associated with OCM, but not with CSM (Table 4).

\section{Discussion}

Treatment decisions for men with non-metastatic prostate cancer are mostly influenced by age and clinical cancer characteristics $[14,15]$. Several previous studies have reported that men with prostate cancer were more likely to die from other causes, not prostate cancer [16,17]. In this study cohort, the overall OCM rate was significantly higher than the prostate CSM rate, which is consistent with most previous studies. In a European study, the survival benefit of radical prostatectomy ranged from $4.5 \%$ to $17.2 \%$ for low- to high-risk patients, in terms of risk reduction of CSM [18]. In a U.S. study that used the Surveillance, Epidemiology, and End Results database, the 10-year CSM rate of patients who underwent radical prostatectomy was $2.8 \%$ compared to $5.8 \%$ in patients assigned to observation [19]. These previous reports indicate that the appropriate selection of patients who will benefit from radical prostatectomy is important because the survival benefit may not be significant in a substantial portion of the patient population. Another important aspect to be taken into consideration in the treatment decision for men with non-metastatic prostate cancer is individual medical comorbidity. Comorbidities are frequent in men diagnosed with prostate cancer and have been associated with mortality after radical treatment [20].

The number of prostate cancer survivors is expected to increase continuously because of demographic changes and advances in treatment methods. Considering the heterogeneity of prostate cancer characteristics and comorbidities according to different geographical and ethnic populations [21,22], in this study, we investigated the cause of death after radical prostatectomy in a Korean cohort. We found that mortality from prostate cancer accounted for only a fraction of the overall mortality in men who underwent radical prostatectomy. Overall, the 10-year prostate CSM and OCM rates after radical prostatectomy in Korean men were similar to those recorded in the United States and European data [16,19,23,24]. The difference between the prostate CSM and OCM rates also varied according to medical comorbidities. Many studies have evaluated the impact of comorbidities on mortality in men with prostate cancer $[7,14,16,19,25,26]$. Consistent with previous findings, our findings showed that comorbidity was independently associated with overall mortality, regardless of age and pathologic features. Our data showed that the rate of mortality from prostate cancer was higher than mortality rate from other causes only in patients with 
Age adjusted $\mathrm{CCl}<3$
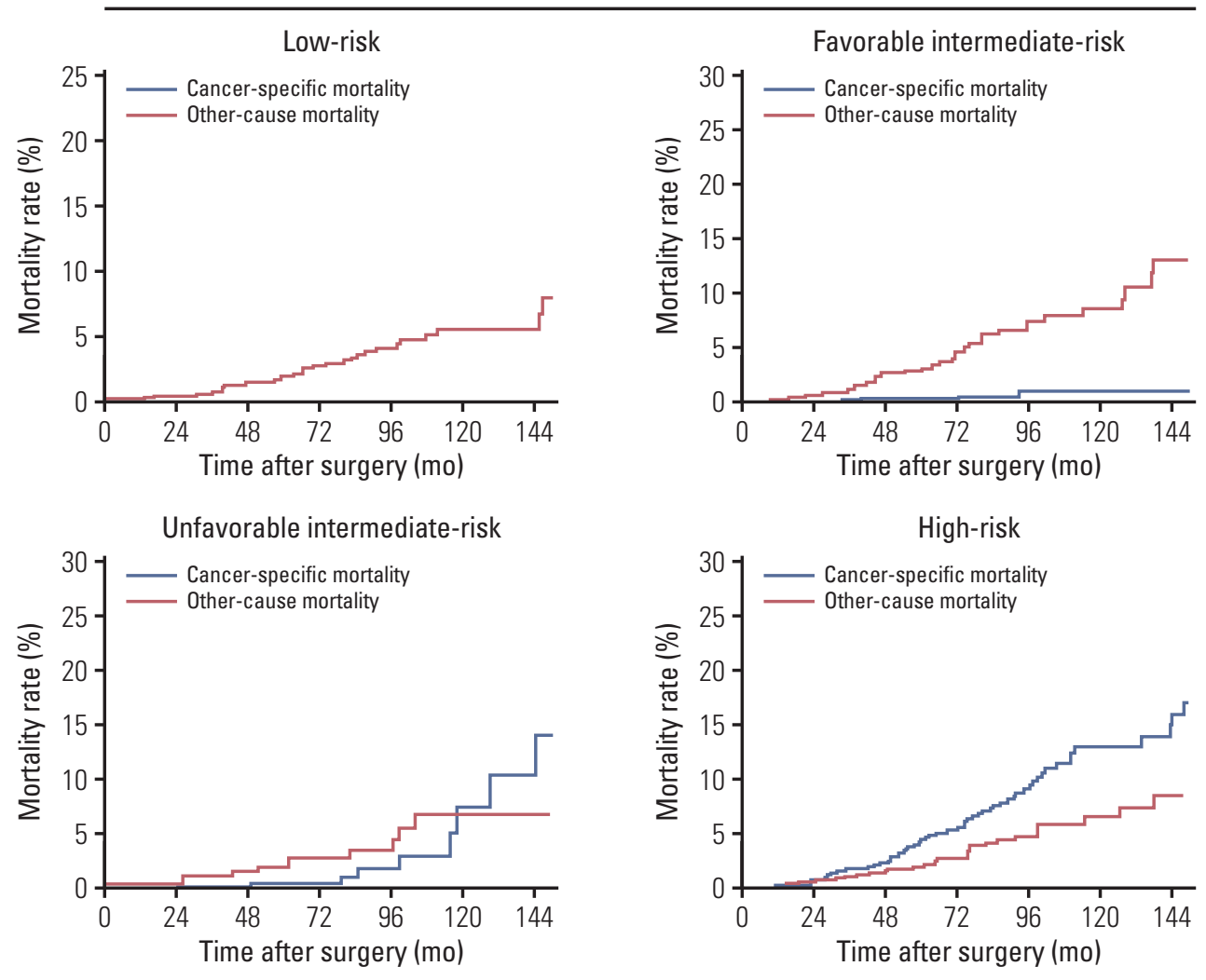

Age adjusted $\mathrm{CCl} \geq 3$
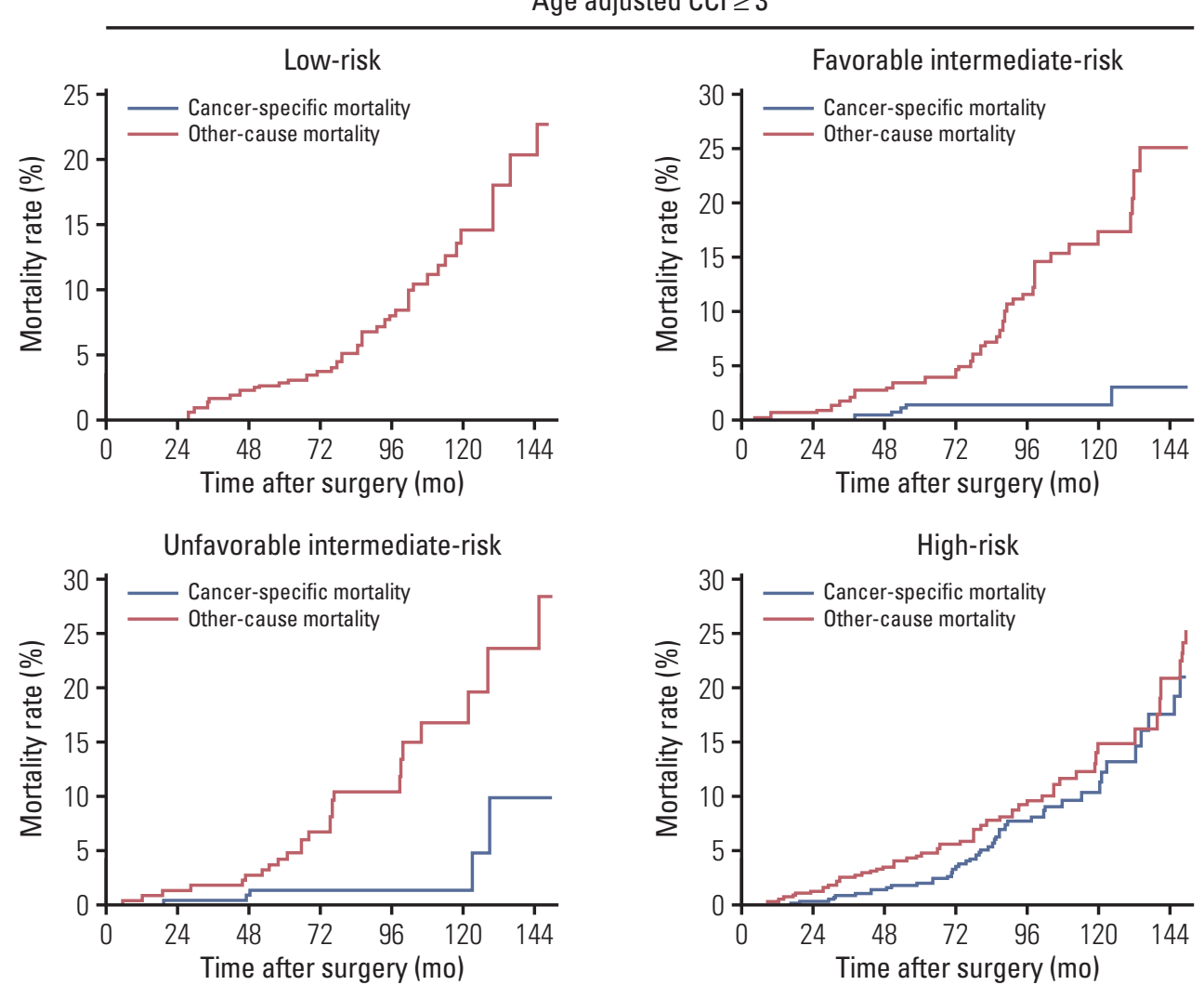

Fig. 3. Survival outcomes according to comorbidities and preoperative National Comprehensive Cancer Network risk group. CCI, Charlson comorbidity index. 
Table 3. Multivariable Cox regression analyses for evaluating the risk of overall mortality

\begin{tabular}{|c|c|c|c|c|c|}
\hline \multirow{2}{*}{ Variable } & \multirow{2}{*}{ No. (event) } & \multicolumn{2}{|c|}{ Univariable } & \multicolumn{2}{|c|}{ Multivariable $^{a}$} \\
\hline & & HR $(95 \% \mathrm{CI})$ & p-value & HR $(95 \% \mathrm{CI})$ & p-value \\
\hline Age & $4,064(447)$ & $1.087(1.070-1.105)$ & $<0.001$ & $1.081(1.063-1.098)$ & $<0.001$ \\
\hline Body mass index & $4,064(447)$ & $0.945(0.912-0.978)$ & 0.002 & - & - \\
\hline \multicolumn{6}{|l|}{ Charlson comorbidity index } \\
\hline $0-1$ & $3,803(370)$ & 1 (reference) & & 1 (reference) & \\
\hline$\geq 2$ & $261(77)$ & $3.236(2.531-4.138)$ & $<0.001$ & $2.964(2.292-3.834)$ & $<0.001$ \\
\hline Prostate-specific antigen & $4,064(447)$ & $1.007(1.005-1.010)$ & $<0.001$ & $1.004(1.000-1.008)$ & 0.048 \\
\hline \multicolumn{6}{|l|}{ Pathologic stage } \\
\hline $\mathrm{T} 2$ & $2,499(206)$ & 1 (reference) & $<0.001$ & 1 (reference) & $<0.001$ \\
\hline $\mathrm{T} 3 \mathrm{a}$ & $942(105)$ & $1.372(1.085-1.736)$ & 0.008 & $1.102(0.860-1.412)$ & 0.444 \\
\hline T3b-N1 & $623(136)$ & $2.750(2.214-3.415)$ & $<0.001$ & $2.194(1.706-2.821)$ & $<0.001$ \\
\hline Pathologic Gleason score & Missing $=129$ & & & & \\
\hline$\leq 3+4$ & $2,277(186)$ & 1 (reference) & $<0.001$ & 1 (reference) & $<0.001$ \\
\hline $4+3$ & $857(77)$ & $1.196(0.916-1.560)$ & 0.188 & $1.003(0.766-1.314)$ & 0.982 \\
\hline $8-10$ & $801(165)$ & 2.447 (1.984-3.018) & $<0.001$ & $1.546(1.222-1.957)$ & $<0.001$ \\
\hline \multicolumn{6}{|l|}{ Surgical margins } \\
\hline Negative & $2,755(267)$ & 1 (reference) & & - & \\
\hline Positive & $1,309(180)$ & $1.405(1.163-1.698)$ & $<0.001$ & - & - \\
\hline
\end{tabular}

$\mathrm{HR}$, hazard ratio; $\mathrm{CI}$, confidence interval. ${ }^{\mathrm{a}}$ Covariates were chosen based on backward selection.

NCCN high-risk disease and low age-adjusted CCI $(<3)$. In this study, we chose the four-tier NCCN risk groups because they have been widely used in current clinical practice. Additionally, we analyzed survival outcomes according to the CAPRA-S scores, and this yielded similar results (S1 Fig.). In patients who had CAPRA-S score $<9$, the 10-year CSM rate was higher than the OCM rate only in those with a CAPRA-S score of 6-8 and age-adjusted CCI of $<3$. The 10year CSM rate was higher than the OCM rate in patients with CAPRA-S score $\geq 9$, regardless of age-adjusted CCI.

In 2018, the mortality rates of the two top causes of death per 100,000 people in Korea were 154.3 for malignant neoplasms and 122.7 for circulatory system diseases [27]. As expected, in this study, we found that other cancers and circulatory system diseases accounted for the majority of nonprostate cancer deaths. In the overall population, the 10-year probability rates of mortality due to other cancers and circulatory system diseases after radical prostatectomy were $4.2 \%$ and $2.2 \%$, respectively. The prostate CSM rate was higher than the mortality rates of other cancers and circulatory system diseases only in high-risk patients (S2 Fig.). In low-risk patients, the mortality rates of other cancers and circulatory system diseases were higher than the prostate CSM rate.

The over-diagnosis and overtreatment of non-metastatic prostate cancer have become a major health care issue [28]. Radical prostatectomy is associated with significant costs and complications. Moreover, common adverse events after surgery, such as incontinence and erectile dysfunction, may have a profound effect on the quality of life of patients. Daskivich et al. [8] reported that men with $\mathrm{CCI} \geq 3$ were treated aggressively in 54\% of cases, indicating that men with lowrisk prostate cancer were often over-treated despite significant comorbidities. Although active surveillance has been widely considered as a standard management modality for low-risk prostate cancer, it has been underutilized, particularly in Asian countries [29,30]. Among the patients who underwent radical prostatectomy in this study cohort, 547 (13.5\%) had low-risk prostate cancer and significant comorbidity (age-adjusted $\mathrm{CCI} \geq 3$ ). In addition, 297 patients $(7.3 \%)$ were eligible for active surveillance (based on the Prostate Cancer Research International Active Surveillance criteria) and had significant comorbidities. These data indicate that a substantial portion of the Korean male population with lowrisk prostate cancer and significant comorbidity underwent radical prostatectomy, which may have led to overtreatment.

We acknowledge several limitations to this study. First, this study was retrospective in nature and could not eliminate the biases inherent to observational studies. Moreover, the lack of prospective standardized protocols for primary and salvage treatment may have introduced biases. Second, the study population may not be representative of all Korean men who undergo radical prostatectomy. Thus, the generalizability of our data from referral centers may be limited. Third, incomplete data on the statistics of the cause of death is another main limitation. These data on the cause of death solely depend on medical records; because of loss to followup, the causes of death in 95 patients $(21.3 \%$ ) were unknown. Few patients had evidence of prostate cancer recurrence until the last follow-up (biochemical recurrence:17/95 [17.9\%] and distant metastasis: $0 / 95[0 \%])$, suggesting that there may 


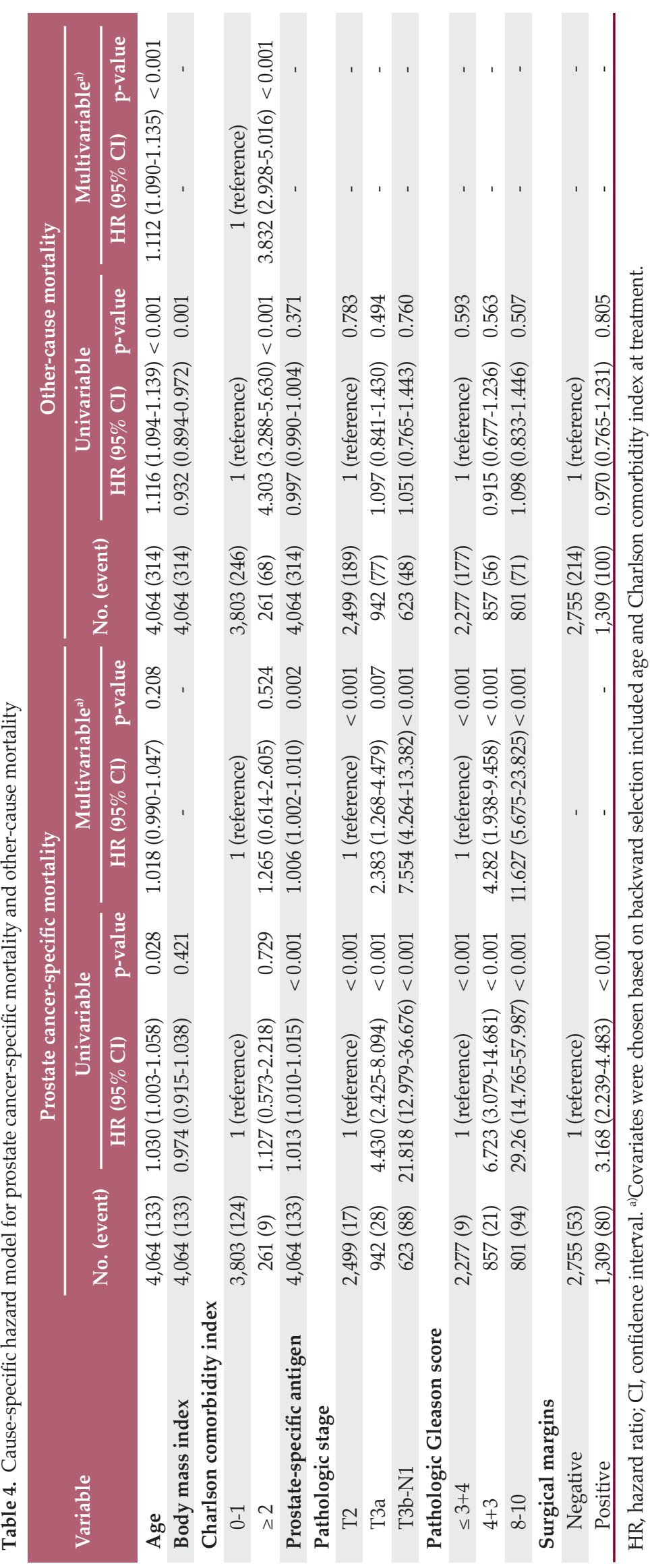


be a larger number of patients who died from other causes than the present data have shown. Fourth, we could not conduct comprehensive geriatric assessment (CGA) in this retrospective study. While CCI provides a quantitative approach to enumerate comorbid conditions, CGA is a multidisciplinary and comprehensive tool for evaluating elderly patients, which may be more appropriate for predicting survival and radical treatment selection. Lastly, the duration and severity of each comorbidity were not taken into consideration.

In conclusion, we have demonstrated that mortality from prostate cancer was rare in Korean men who underwent radical prostatectomy. Physicians should be aware of the possibility of overtreatment for low-risk prostate cancer in men with significant comorbidity. These findings may help to facilitate counseling and plan management in this patient group.

\section{Electronic Supplementary Material}

Supplementary materials are available at Cancer Research and Treatment website (https:// www.e-crt.org).

\section{Conflicts of Interest}

Conflicts of interest relevant to this article was not reported.

\section{Acknowledgments}

This work was supported by a career development award (NCCCDA2019-06) from the National Cancer Center, Korea.

\section{References}

1. Miller KD, Nogueira L, Mariotto AB, Rowland JH, Yabroff KR, Alfano CM, et al. Cancer treatment and survivorship statistics, 2019. CA Cancer J Clin. 2019;69:363-85.

2. ICECaP Working Group; Sweeney C, Nakabayashi M, Regan M, Xie W, Hayes J, et al. The Development of Intermediate Clinical Endpoints in Cancer of the Prostate (ICECaP). J Natl Cancer Inst. 2015;107:djv261.

3. Tosoian JJ, Carter HB, Lepor A, Loeb S. Active surveillance for prostate cancer: current evidence and contemporary state of practice. Nat Rev Urol. 2016;13:205-15.

4. Wilt TJ, Jones KM, Barry MJ, Andriole GL, Culkin D, Wheeler $\mathrm{T}$, et al. Follow-up of prostatectomy versus observation for early prostate cancer. N Engl J Med. 2017;377:132-42.

5. Mahmood U, Levy LB, Nguyen PL, Lee AK, Kuban DA, Hoffman KE. Current clinical presentation and treatment of localized prostate cancer in the United States. J Urol. 2014;192: 1650-6.

6. Sarfati D, Koczwara B, Jackson C. The impact of comorbidity on cancer and its treatment. CA Cancer J Clin. 2016;66:337-50.

7. Daskivich TJ, Kwan L, Dash A, Saigal C, Litwin MS. An age adjusted comorbidity index to predict long-term, other cause mortality in men with prostate cancer. J Urol. 2015;194:73-8.

8. Daskivich TJ, Chamie K, Kwan L, Labo J, Palvolgyi R, Dash A, et al. Overtreatment of men with low-risk prostate cancer and significant comorbidity. Cancer. 2011;117:2058-66.

9. Roder MA, Brasso K, Christensen IJ, Johansen J, Langkilde NC, Hvarness H, et al. Survival after radical prostatectomy for clinically localised prostate cancer: a population-based study. BJU Int. 2014;113:541-7.

10. Satariano WA, Ragland KE, Van Den Eeden SK. Cause of death in men diagnosed with prostate carcinoma. Cancer. 1998;83:1180-8

11. Charlson M, Szatrowski TP, Peterson J, Gold J. Validation of a combined comorbidity index. J Clin Epidemiol. 1994;47:124551.

12. Mohler JL, Antonarakis ES, Armstrong AJ, D'Amico AV, Davis BJ, Dorff T, et al. Prostate cancer, version 2.2019, NCCN clinical practice guidelines in oncology. J Natl Compr Canc
Netw. 2019;17:479-505.

13. Cooperberg MR, Hilton JF, Carroll PR. The CAPRA-S score: A straightforward tool for improved prediction of outcomes after radical prostatectomy. Cancer. 2011;117:5039-46.

14. Matthes KL, Limam M, Pestoni G, Held L, Korol D, Rohrmann S. Impact of comorbidities at diagnosis on prostate cancer treatment and survival. J Cancer Res Clin Oncol. 2018;144:70715.

15. Boehm K, Larcher A, Tian Z, Mandel P, Schiffmann J, Karakiewicz PI, et al. Low other cause mortality rates reflect good patient selection in patients with prostate cancer treated with radical prostatectomy. J Urol. 2016;196:82-8.

16. Briganti A, Spahn M, Joniau S, Gontero P, Bianchi M, Kneitz B, et al. Impact of age and comorbidities on long-term survival of patients with high-risk prostate cancer treated with radical prostatectomy: a multi-institutional competing-risks analysis. Eur Urol. 2013;63:693-701.

17. Matthes KL, Pestoni G, Korol D, Van Hemelrijck M, Rohrmann S. The risk of prostate cancer mortality and cardiovascular mortality of nonmetastatic prostate cancer patients: a population-based retrospective cohort study. Urol Oncol. 2018;36:309.

18. Vickers A, Bennette C, Steineck G, Adami HO, Johansson JE, Bill-Axelson A, et al. Individualized estimation of the benefit of radical prostatectomy from the Scandinavian Prostate Cancer Group randomized trial. Eur Urol. 2012;62:204-9.

19. Abdollah F, Sun M, Schmitges J, Thuret R, Bianchi M, Shariat $\mathrm{SF}$, et al. Survival benefit of radical prostatectomy in patients with localized prostate cancer: estimations of the number needed to treat according to tumor and patient characteristics. J Urol. 2012;188:73-83.

20. Ketchandji M, Kuo YF, Shahinian VB, Goodwin JS. Cause of death in older men after the diagnosis of prostate cancer. J Am Geriatr Soc. 2009;57:24-30.

21. Boyd LK, Mao X, Lu YJ. The complexity of prostate cancer: genomic alterations and heterogeneity. Nat Rev Urol. 2012;9: 652-64.

22. Jeong IG, Dajani D, Verghese M, Hwang J, Cho YM, Hong $\mathrm{JH}$, et al. Differences in the aggressiveness of prostate cancer 
among Korean, Caucasian, and African American men: a retrospective cohort study of radical prostatectomy. Urol Oncol. 2016;34:3.

23. Eggener SE, Scardino PT, Walsh PC, Han M, Partin AW, Trock BJ, et al. Predicting 15-year prostate cancer specific mortality after radical prostatectomy. J Urol. 2011;185:869-75.

24. Bolton DM, Papa N, Ta AD, Millar J, Davidson AJ, Pedersen $\mathrm{J}$, et al. Predictors of prostate cancer specific mortality after radical prostatectomy: 10 year oncologic outcomes from the Victorian Radical Prostatectomy Registry. BJU Int. 2015;116 Suppl 3:66-72.

25. Daskivich TJ, Fan KH, Koyama T, Albertsen PC, Goodman M, Hamilton AS, et al. Prediction of long-term other-cause mortality in men with early-stage prostate cancer: results from the Prostate Cancer Outcomes Study. Urology. 2015;85:92-100.

26. Rajan P, Sooriakumaran P, Nyberg T, Akre O, Carlsson S, Ege- vad L, et al. Effect of comorbidity on prostate cancer-specific mortality: a prospective observational study. J Clin Oncol. 2017;35:3566-74.

27. Vital Statistics Division, Statistics Korea, Shin HY, Lee JY, Kim JE, Lee S, Youn H, et al. Cause-of-death statistics in 2016 in the Republic of Korea. J Korean Med Assoc. 2018;61:573-84.

28. Etzioni R, Mucci L, Chen S, Johansson JE, Fall K, Adami HO. Increasing use of radical prostatectomy for nonlethal prostate cancer in Sweden. Clin Cancer Res. 2012;18:6742-7.

29. Jeong IG, Yoo S, Lee C, Kim M, You D, Song C, et al. Obesity as a risk factor for unfavorable disease in men with low risk prostate cancer and its relationship with anatomical location of tumor. J Urol. 2017;198:71-8.

30. Loppenberg B, Friedlander DF, Krasnova A, Tam A, Leow JJ, Nguyen PL, et al. Variation in the use of active surveillance for low-risk prostate cancer. Cancer. 2018;124:55-64. 